\title{
Riglyn 4.003 vir inkomstebepaling: 'n Teoretiese beoordeling
}

\author{
I.J. Lambrechts en P. van Eeghen \\ Departement Bedryfsekonomie, Universiteit van Stellenbosch, Stellenbosch
}

\begin{abstract}
Guideline 4.003 for income determination: A theoretical evaluation. During the last few years the distribution and realization principles began to play an increasingly important role in literature. The income of an organization is increasingly viewed as the cash amount that can be withdrawn without hampering the continuity of ongoing action. The purpose of an in. come system, like the South African guideline 4.003, is to render an index of the income which can be utilized for expansion and/or distribution. There is always a reasonably large optimism and trust in the reliability of guideline 4.003 to accomplish this. The present article highlights some weaknesses of guideline 4.003 which cannot be ignored.

These weaknesses are related to the assumption regarding the realization of purchasing income on loans, the calculation of net monetary assets and liabilities, the calculation of loss of purchasing power on distributable income and depreciation and the revaluation of equity capital of the balance sheet. $A$ complete distribution of income according to guideline 4.003 is therefore not always without problems for continuity and is also not necessarily a reliable point of departure for a divided policy during inflation.

S. Afr. J. Bus. Mgmt. 1984, 15: $67-70$
\end{abstract}

Gedurende die afgelope aantal jare het die uitkeerbaarheidsen realisasiebeginsel ' $n$ al hoe groter rol begin speel in die literatuur. Die inkomste word meer en meer beskou as die kontantbedrag wat aan die onderneming onttrek kan word sonder dat dit die kontinuïteit van sy huidige aktiwiteite benadeel. Die doel van 'n inkomstebepalingsisteem soos die Suid-Afrikaanse riglyn 4.003 is om 'n inkomstesyfer te lewer wat beskikbare kontant vir uitbreiding en/of uitkering verteenwoordig. Daar is deurgaans ' $n$ redelike groot optimisme en vertroue in die betroubaarheid van riglyn $4.003 \mathrm{om}$ die doel te bereik. In hierdie artikel word egter gewys op tekortkomings van riglyn 4.003 wat nie verontagsaam kan word nie.

Hierdie tekortkomings staan in verband met 'n aanname betreffende die realisasie van koopkraginkomste op lenings, die berekening van netto monetêre bates en laste, die berekening van koopkragverliese op uitkeerbare inkomste en afskry. wing, en die herwaardering van die eie kapitaal op die eindbalansstaat. ' $n$ Volledige uitkering van die inkomste volgens riglyn 4.003 is gevolglik nie altyd sonder probleme vir kontinuitteit nie en dit is ook nie noodwendig 'n betroubare uitgangspunt vir 'n dividendbeleid tydens inflasie nie. S.-Afr. Tydskr. Bedryfsl. 1984, 15: 67-70

\section{I.J. Lambrechts* en P. van Feghen}

Departement Bedryfse'ionomie, Universiteit van Stellenbosch, Stellenbosch, 7600 Republiek van Suid-Afrika

*Aan wie korrespondensie gerig moet word

\section{Inleiding}

Gedurende die afgelope aantal jare het die uitkeerbaarheidsen realisasiebeginsel ' $n$ steeds groter rol begin speel in die literatuur oor inkomstebepaling. Die inkomste word meer en meer beskou as die kontantbedrag wat aan die onderneming onttrek kan word sonder dat dit die kontinuïteit van sy huidige aktiwiteite benadeel. Nie die handhawing van die reële waarde van die eie kapitaal (die aandeelhouersbelang) nie, maar die beveiliging van die reële waarde van die onderneming se bates word as uitgangspunt geneem. Die verskil is dat ook rekening gehou word met die invloed van relatiewe prysverskille (prysveranderinge in afwyking van 'n algemene koopkragindeks) op die kapitaal nodig vir die handhawing van die huidige aktiwiteite. Die oorskot is dan die inkomste wat beskikbaar is vir rasionele uitkering en/of die interne finansiering van uitbreiding. Indien daar gedurende die jaar geen uitbreidingsinvesterings was nie (in monetêre of nie-monetêre bates) is hierdie inkomste volledig in kontantvorm beskikbaar.

Die bostaande filosofie vir inkomstebepaling was in breë trekke die agtergrond vir die vervangingswaardeleer, in die tradisie van die Nederlandse bedryfsekonome Limperg en v.d. Schroeff (behalwe dat hulle oorspronklik slegs relatiewe prysverskille in oënskou geneem het en koopkragveranderings van geld verontagsaam het). Hierdie soort van denke oor inkomste het ook steeds meer ingang gevind in die Angelsaksiese wêreld, waar dit bekend staan as 'current cost accounting'. Ook die opstellers van die Suid-Afrikaanse riglyn het hierdie filosofie as uitgangspunt geneem. Hiervan getuig die feit dat riglyn 4.003 gerig is op die handhawing van die reële waarde van die ondernemingsbates (en nie die van eie kapitaal nie) alvorens daar sprake van inkomste is. Gevolglik word ook rekening gehou met relatiewe prysveranderinge en koopkraginkomste op monetêre laste by die vasstelling van die addisionele kapitaalbehoeftes as gevolg van prysstygings.

Die doelwit met hierdie artikel is om aan te toon dat die manier waarop riglyn 4.003 bostaande uitgangspunt vir inkomstebepaling ten uitvoer bring aan sekere gebreke onderhewig is. Hiermee wil ons nie te kenne gee dat riglyn 4.003 ontoepasbaar of van geen nut is nie. Trouens, riglyn 4.003 was wat Suid-Afrika betref, 'n groot stap vorentoe en die vertroue word uitgespreek dat dit nie noodwendig as die finale antwoord gesien moet word nie. Daar sal aangetoon word dat riglyn 4.003 nie so goed met die netto-kontantstroom korreleer as wat algemeen aanvaar word nie ${ }^{1}$.' $n$ Volledige uitkering van die inkomste bereken volgens riglyn 4.003 is gevolglik nie altyd sonder benadeling van die kontinuiteit nie en dit is dus ook nie noodwendig ' $n$ betroubare uitgangspunt vir' $n$ dividendbeleid 
tydens inflasie nie.

\section{Die tekortkoming van riglyn $4.003^{2}$}

Teen die eerste twee aansuiwerings van die historiese inkomste wat voortspruit uit riglyn 4.003 bestaan daar min besware. Die toename van die benodigde investering in duursame bates en voorrade as gevolg van prysstygings word op 'n bevredigende wyse bereken. Die besware rig hul veral teen die manier waarop die koopkragresultate op monetêre bates en laste in die inkomste verwerk word. Die gebreke van riglyn 4.003 in die verband sal hieronder puntsgewys uiteengesit word.

Eerste beswaar: 'n Foutiewe realisasie-beginsel vir koopkraginkomste op lenings

Soos uit die berekeningswyse van die hefboomaansuiwering blyk, veronderstel riglyn 4.003 dat koopkraginkomste op monetêre laste gerealiseer word op die moment van verkoop van nie-monetêre bates, of by die omskepping daarvan, vir die deel wat hulle met vreemde kapitaal gefinansier word. Dit berus op 'n misverstand. Koopkraginkomste op monetêre laste word nie by die verkoop van die betrokke bates in die transaksie-inkomste gerealiseer nie, maar wel by die aangaan van 'n addisionele lening. Hierdie punt kan deur ' $n$ baie eenvoudige voorbeeld verduidelik word.

Gestel 'n hipotetiese geval van 'n onderneming met slegs een nie-monetêre bate van $\mathrm{R} 100$ wat jaarliks eenmaal verkoop word vir R120 en daarna weer vervang word. Hierdie onderneming het aanvanklik geen monetêre bates nie en is vir die helfte met lenings gefinansier. Die begin- en eindbalansstate lyk soos volg:

Beginbalansstaat

\begin{tabular}{llll}
\hline Eie kapitaal & 50 & Bate & 100 \\
Lenings & 50 & &
\end{tabular}

Eindbalansstaat

$\begin{array}{lllr}\text { Eie kapitaal } & 50 & \text { Bate } & 100 \\ \text { Inkomste } & 20 & \text { Kontant } & 20 \\ \text { Lenings } & 50 & & \end{array}$

Net na inkomste-uitkering van die volle inkomste aan die begin van die daaropvolgende jaar vind ' $n$ uniforme styging van alle pryse met $10 \%$ plaas. Die vervangingsprys word gevolglik 1,10 $\times \mathrm{R} 100=\mathrm{R} 110$ en die verkoopprys $1,10 \times \mathrm{R} 120=\mathrm{R} 132$. Die begin- en eindbalansstate van die betrokke jaar gaan nou soos volg lyk:

Beginbalansstaat

\begin{tabular}{llll}
\hline Eie kapitaal & 50 & Bate & 100 \\
Lenings & 50 & &
\end{tabular}

\section{Eindbalansstaat}

$\begin{array}{lllr}\text { Eie kapitaal } & 50 & \text { Bate } & 110 \\ \text { Inkomste } & 32 & \text { Kontant } & 22 \\ \text { Lenings } & 50 & & \end{array}$

Uit die eindbalansstaat blyk dat by die verkoop van die bate nog geen koopkraginkomste op lenings gerealiseer word nie. Die beskikbare kontant is R22, wat slegs ' $n$ inflasionêre verhoging van die oorspronklike transaksie-inkomste van $R 20$ is. Die finansieringsinkomste op lenings word eers gerealiseer wanneer 'n ekstra bedrag geleen word om sodoende die reële kapitaalstruktuur te handhaaf. $\mathrm{Na}$ 'n addisionele lening van
$10 \% \times \mathrm{R} 50=\mathrm{R} 5$ en na herwaardering van die eie kapitaal lyk die eindbalansstaat soos volg: ${ }^{3}$

Eindbalansstaat

\begin{tabular}{lrlr}
\hline Eie kapitaal & 55 & Bate & 110 \\
Lenings & 55 & Kontant & 27 \\
Inkomste & 27 & &
\end{tabular}

Die bevinding dat koopkraginkomste op lenings slegs gerealiseer word deur 'n addisionele lening het twee belangrike gevolge vir inkomstebepaling. Eerstens kan die koopkraginkomste op lenings slegs tot die uitkeerbare inkomste gereken word in die mate dat hierdie lening ook werklik plaasgevind het. Dit is immers in geen geval seker dat die onderneming hierdie bedrag reeds geleen het nie. Dit mag selfs so wees dat hy dit nooit sal doen nie. Dit bring ons by die tweede belangrike gevolg. So 'n regstreekse uitkering van eksterne leningsfondse mag uiteraard nie ten koste van finansiële risiko wees nie. Uitsluitend vir sover die ekstra lening die finansiële risiko nie verhoog nie, mag dit as uitkeerbare koopkraginkomste beskou word, want anders sou dit die kontinuiteit kon benadeel. Om hierdie bedrag vas te stel, is ' $n$ blik op die balansstaat nie voldoende nie. Dit is immers nie die nominale waarde van die eie kapitaal nie, maar die huidige en verwagte rentedekking wat die kredietkapasiteit en die finansiële risiko bepaal. Uitgaande van 'n sekere vereiste rentedekking sal daar vasgestel moet word wat die invloed van inflasie op die bedrag beskik. baar vir rentebetalings is. Sowel die heersende kredietwaardigheid vir nuwe lenings as die rente op bestaande lenings sal vervolgens tesame bepaal hoeveel bygeleen kan word. Aangesien inflasie die kontantstroom ook reëel negatief kan beinvloed (veral by 'n stygende inflasietempo) en die rentevoet ook kan styg, hoef die koopkraginkomste op lenings geensins noodwendig volledig gerealiseer te word nie.

Dit moet nogmaals benadruk word dat die invloed van reële faktore op die kontantstroom buite beskouing gelaat moet word, aangesien die positiewe invloed wat dit op die kredietkapasiteit kan hê uiteraard nie uitgekeer moet word nie. Dit is egter nie altyd moontlik om reële van inflasionêre faktore te skei nie. Moet afwentelingsinkomste of- verliese (as gevolg van oorvolledige of ondervolledige afwenteling van kostestygings) byvoorbeeld volledig aan inflasie of ook aan reële faktore (soos mededingingsverhoudings in die mark) toegeskryf word? Verder kan faktore soos veranderde strukturele sakevooruitsigte meebring dat die vereiste rentedekking, wat as uitgangspunt geneem is, aangepas moet word. In so 'n geval sal die berekening nog subjektiewer raak, aangesien by die bepaling van die absolute omvang van die kredietkapasiteit subjektiewe elemente 'n groot rol speel.

Samevattend, kan met betrekking tot die vasstelling van die koopkraginkomste op lenings die volgende gestel word:

- koopkraginkomste op lenings word slegs gerealiseer deur middel van ' $n$ addisionele lening en nie in die transaksieinkomste nie;

- die omvang van die addisionele leningsmoontlikheid word bepaal aan die hand van die invloed van inflasie op die beskikbare ruimte vir rentebetalings gegewe 'n sekere rentedekking; die aantrekking van hierdie addisionele lening mag die finansiële risiko immers nie vermeerder nie;

- die invloed van reële en inflasionêre faktore op die beskikbare ruimte vir rentebetalings kan nie op 'n volledige objektiewe wyse geskei word nie;

- indien die onderneming sy finansiële beleid en dus die vereiste rentedekking wil verander, gaan verdere sub- 
jektiewe faktore 'n rol speel;

- die omvang van die potensiële koopkraginkomste op lenings is gevolglik streng gesproke onmoontlik objektief en presies te bepaal.

Origens geld die eksterne realisering van koopkraginkomste slegs met betrekking tot lenings. Koopkraginkomste op handelskrediteure kan wel spontaan intern gerealiseer word, soos die kredietbedrag outomaties styg as gevolg van stygende inkooppryse. ${ }^{4}$

Tweede beswaar: Berekening van netto monetêre bates en laste

Die berekening van netto monetêre bates en laste is om twee redes onaanvaarbaar, naamlik:

(i) Koopkragverliese op monetêre bates word altyd volledig gerealiseer, maar koopkraginkomste op lenings geensins. Gevolglik is dit nie korrek om monetêre bates en lenings van mekaar af te trek en die koopkragresultaat op die verskil te bepaal nie.

(ii) Vir elke monetêre item kan as gevolg van verskillende spesificke prysstygingspersentasies, ook verskillende koopkraginkomste/-verlies-persentasies geld. Hierdie feit word verontagsaam indien alle monetêre items saamgeneem word, tensy 'n korrekte geweegde gemiddelde van alle spesifieke prysstygingspersentasies gebruik word.

Derde beswaar: Berekening van koopkragverlies op uitkeerbare inkomste en afskrywing

Riglyn 4.003 gebruik onder andere die bedrae in die eindbalansstaat vir die berekening van die gemiddelde posisie gedurende die jaar, indien daar groei is. Dit is om twee redes verkeerd.

(i) By die eindbalansstaatbedrae van kontant kan veronderstel word dat dit deels die uitkeerbare inkomste van die betrokke jaar insluit ${ }^{5}$ waarop daar geen koopkragverlies bereken mag word nie. Koopkragverlięs op die inkomste sou immers uit die inkomste self goedgemaak moet word.

(ii) By 'n nie-harmonieuse opbou van die lewensduurte van die duursame bates (geen 'ideaalkompleks'), kan daar in 'n mate fondsvorming van die afskrywingsbedrae plaasvind. Die bedrag in die eindbalansstaat vir kontant bevat dan deels ook die afskrywingsbedrag, waarvoor die koopkragverlies dan reeds by die eerste inkomsteregstelling voorsien is. Sodoende kan 'n dubbeltelling ontstaan.

Vierde beswaar: Foutiewe herwaardering van die eie kapitaal op die eindbalansstaat

Volgens riglyn 4.003 moet die eie kapitaal op die eindbalansstaat eers geherwaardeer word, alvorens die hefboomverhouding bepaal kan word. Hierdie herwaardering geskied deur die nominale waardetoename van alle reële bates by die eie kapitaal te tel. Ten onregte word dan implisiet veronderstel dat al daardie bates met eie kapitaal gefinansier is. Eintlik sou slegs die nominale waardetoename van bates vir die deel wat hulle gemiddeld met eie kapitaal gefinansier is, by wyse van herwaardering by die eie kapitaal getel moet word. Die probleem is egter dat dit die bekendheid van die gemiddelde kapitaalstruktuur reeds voorveronderstel terwyl ons juis op soek is daarna.

\section{Moontlikhede vir hersiening}

'n Inkomstebepalingsisteem is in 'n mate altyd 'n kompromis tussen teoretiese korrektheid en praktiese hanteerbaarheid en dit is belangrik om dit in aanmerking te neem wanneer aan moontlikhede vir verbetering gedink word.

Hieronder word enkele rigtings waarin verbeterings van die hefboomregstelling gesoek sou kon word, aangegee.

(i) In algemene terme gestel, moet die volgende twee inkomste-aansuiwerings gemaak word om rekening te hou met die invloed van prysstygings op die uitkeerbare inkomste:

- die addisionele noodsaaklike investering in monetêre en nie-monetêre bates as gevolg van prysstygings; en

- die gerealiseerde addisionele finansieringsmoontlikhede met monetêre laste as gevolg van prysstygings, sonder dat dit ten koste van addisionele finansiële risiko is.

(ii) In beginsel moet die invloed van prysstygings op elke balansstaatitem afsonderlik bepaal word, aangesien vir elk 'n ander spesifieke prysstyging kan geld. Eenvoudigheidshalwe sou debiteure en krediteure egter ook saamgeneem kon word met gebruikmaking van 'n gemiddelde prysstygingspersentasie, sonder dat te groot foute gemaak hoef te word.

(iii) Om te voorkom dat koopkragverliese op die inkomstebedrag van die betrokke jaar self en op die afskrywingsbedrag van hierdie jaar (in die geval van afwesigheid van 'n 'ideaalkompleks'), moet 'n metode gevind word om die toename/afname in kontant gedurende die jaar te bereken sonder dat van die eindbedrag gebruik gemaak word. 'n Moontlike oplossing is om die toename/afname te bereken aan die hand van die veranderings wat in die orige balansstaatposte plaasgevind het. Elke verandering is immers gekoppel aan ' $n$ ooreenstemmende verandering in die kontantposisie.

(iv) 'n Omvattende en subjektiewe berekening is nodig om die eventuele byleningsmoontlikheid as die suiwere gevolg van inflasie te bepaal. Verdere navorsing sal gedoen moet word om praktiese benaderings te vind.

(v) Die probleem van onbepaalbaarheid van die gemiddelde kapitaalstruktuur is nie relevant nie, aangesien dit geen rol meer speel by die berekening van koopkraginkomste op lenings nie.

\section{Samevatting}

Die doel van ' $n$ inkomstebepalingsisteem soos riglyn 4.003 is om ' $n$ inkomstesyfer te lewer wat in kontant beskikbaar is vir uitkering en/of uitbreiding. ${ }^{6}$ In hierdie artikel is die aandag gevestig op gebreke van riglyn 4.003 in dié verband. Daar is gewys op sekere tekortkominge in die manier waarop koopkragresultate gehanteer word. Die belangrikste punte van kritiek was die volgende:

- verontagsaming van die feit dat koopkraginkomste op lenings gerealiseer word vir sover inflasie 'n addisionele lening moontlik maak sonder dat dit ten koste van finansiële risiko is;

- berekening van netto monetêre bates en laste, omdat daar ten onregte implisiet veronderstel word dat koopkraginkomste op lenings altyd volledig gerealiseer word, maar ook omdat dan verontagsaam word dat verskillende persentasies op verskillende monetêre bates en laste van toepassing is;

- die berekening van koopkragverlies op die inkomstebedrag van die betrokke jaar self en ook by geen 'ideaalkompleks' op die afskrywingsbedrag is foutief;

- die foutiewe metode van herwaardering van die eie kapitaal op die eindbalansstaat vir die bepaling van die gemiddelde kapitaalstruktuur gedurende die jaar.

Vir sover geen oplossings vir tekortkominge van riglyn 4.003 
aangebied is nie, is rigtings aangedui waarin verdere navorsing kan plaasvind.

\section{Summary}

During the past number of years the distribution and realization principles received more and more attention in the literature. There is a modern trend to view income as the cash amount which could be paid out as dividends without affecting the continuity of an undertaking detrimentally. The point of departure is the maintenance of the real value of an undertaking's assets and not that of the equity capital. Account is also taken of the influence of relative price differences (specific price changes compared to general price changes) on capital requirements for the maintenance of present activities. The surplus is then available for rational distribution and/or the internal financing of expansion.

The objective of an income determination system as described above is what the South African guideline 4.003 wants to attain. Guideline 4.003 is a step in the correct direction but it should not be seen as the final answer. This article summarizes a number of shortcomings (problems) of guideline 4.003 which cannot be ignored. Hence full pay-out of income based on guideline 4.003 can be to the detriment of continuity and is not always a sound basis for dividend policy in times of inflation.

The most important points of criticism raised against guideline 4.003 in this article are the following:

(i) It ignores the fact that purchasing power income on loans is only realized if inflation enables a company to obtain an additional loan without increasing the financial risk.

(ii) The calculation of net monetary assets and liabilities because it is incorrectly assumed that purchasing power income on loan capital is always realized fully and also because different percentages apply to different monetary assets and liabilities.

(iii) The calculation of the purchasing power loss on the undistributed income of a specific year and also in the case of no 'ideal complex' of assets is wrong.

(iv) The revaluation of equity capital on the last balance sheet to determine the average financial structure is incorrect.

Certain suggestions are made to improve the reliability of Guideline 4.003 and directions for further refinement are also indicated.

\section{Aantekeninge}

1. Sien bv. Hamman, W.D. 1979. S.A. Guideline 4.003 and Cash Flow. The S.A. Chartered Accountant, Mei, bl. 181-184.

2. Die basiese inhoud van riglyn 4.003 sal in die artikel as bekend veronderstel word. Verder sal eenvoudigheidshalwe slegs die volgende balansstaatitems in oënskou geneem word (waarby van klassifikasieprobleme afgesien word): kontant en debiteure (monetêre bates), voorrade en duursame produksiemiddele (nie monetêre bates), krediteure en lenings (monetêre laste) en eie kapitaal (nie-monetêre laste).

3. Herwaardering van eie kapitaal is nie streng volgens riglyn 4.003 nie. Sien ook in die verband die vierde beswaar teen riglyn 4.003 .

4. Dit geld slegs vir sover die kredietgewer sy krediettermyn nie verminder nie as vorm van afwenteling van die koopkragverlies wat hy op die betrokke bedrag ly.

5. Die inkomste is in kontantvorm aanwesig indien daar geen uitbreidingsinvestering gedurende die jaar was nie of indien veronderstel word dat die uitbreidingsinvesterings nie uit dic inkomste van die betrokke jaar self gefinansier is nie.

6. Indien daar gedurende die jaar reeds uitbreidingsinvesterings in monetêre en nie-monetêre bates was, dan is die inkomstebedrag uiteraard nie volledig in kontantvorm beskikbaar nie. 